\title{
Syncope due to acute rheumatic fever with pacemaker-like syndrome
}

\author{
Denizhan Bağrul \\ Department of Pediatric Cardiology, Rize Recep Tayyip Erdoğan University, Training and Research Hospital, Rize, Turkey. \\ E-mail: denizhanbagrul@hotmail.com \\ Received: 2nd August 2018, Revised: 10th October 2018, Accepted: 19th October 2018
}

SUMMARY: Bağrul D. Syncope due to acute rheumatic fever with pacemakerlike syndrome. Turk J Pediatr 2019; 61: 810-814.

The prolongation in the PR interval on the electrocardiogram is one of the minor criteria of Jones. Abnormal increases in the PR interval lead to hemodynamic impairments caused by atrioventricular asynchrony and is called pseudo-pacemaker or pacemaker-like syndrome in the literature. A 13-yearold boy who had polyarthralgia for six weeks was referred to the emergency room because of syncope while exerting effort. In the electrocardiography, the $P$ wave was regularly seen at the onset of the $T$ wave immediately after the QRS wave with extremely prolonged PR interval and mild tachycardia. Also, 24 hours rhythm Holter recording showed atrioventricular dissociation. The echocardiography revealed findings of severe carditis. Diagnosis of acute rheumatic fever accompanying pacemaker-like syndrome was made. Although the recommendation for marked first-degree atrioventricular block that causes hemodynamic impairment is pacemaker implantation, a significant improvement in the PR prolongation was observed in the short term with anti-inflammatory treatment because the impairment of conduction in the patient was due to inflammation. The pacemaker-like syndrome in a child is being reported for the first time in the literature.

Key words: acute rheumatic fever, cardiac conduction system, pacemaker-like syndrome, atrioventricular dissociation.

Acute rheumatic fever, is a complication of group A beta-hemolytic streptococcal infection affecting the heart, joints, and central nervous system in children and adolescents. The disease, whose diagnostic criteria first emerged in 1944 as defined by Jones, still confronts us as a problem in developing countries. The $\mathrm{PR}$ prolongation in electrocardiography is used as a minor criterion. ${ }^{1,2}$ Clarke and Keith described prolonged PR intervals of $84 \%$ of 508 children with acute rheumatic fever. ${ }^{3}$ The PR interval for those between 10-15 years old is 0.12-0.19 seconds. ${ }^{4}$ The PR segment above 0.20 seconds is called a prolonged PR interval. The PR interval above 0.30 seconds is called a marked first-degree atrioventricular block. ${ }^{5}$ The hemodynamic impairment that atrioventricular asynchrony causes are a result of a decrease in cardiac output and syncope. Also, electrocardiographic changes can be confused with other rhythmic disorders and can cause diagnostic difficulties.

\section{Case Report}

A 13-year-old boy was brought to the emergency room because of syncope. In the patient's history, it was learned that he had pain in both of his knees for six weeks and that he had pain and tenderness in the axial skeleton for three weeks, especially in the segments of his thoracal vertebrae, that because of this he was seen by an orthopedist and that no treatment was given. On the morning of the referral, he was brought to the emergency room because of syncope when he exerted effort. In the physical examination, heart rate was 130/minute, blood pressure was 100/65 $\mathrm{mmHg}$, and body temperature was $36.9{ }^{\circ} \mathrm{C}$. The cardiac auscultation revealed a pansystolic 
murmur, grade 2-3 out of 6 over the apex and radiating to the left axilla and an early diastolic murmur heard at the left and right side of the sternum. The laboratory findings were reported as follows: white blood cell count, 13,2×10\%/L; hemoglobin level, $11.2 \mathrm{~g} / \mathrm{L}$; platelet count of $245 \times 10^{9} / \mathrm{L}$; C-reactive protein level, $33 \mathrm{mg} / \mathrm{L}$; erythrocyte sedimentation rate, $62 \mathrm{~mm} / \mathrm{h}$; anti-streptolysin O titer, 720 $\mathrm{IU} / \mathrm{mL}$. The neurological examination and other systematic examinations were normal. In the electrocardiography, the mild sinus tachycardia and the $\mathrm{P}$ wave was regularly seen at the onset of the $\mathrm{T}$ wave immediately after the QRS wave (Fig. 1 a-b). The delay of atrioventricular conduction (first-degree atrioventricular block) was present at levels that could be confused with the retrograde conduction $\mathrm{P}$ wave in the electrocardiography. In the echocardiography, significant mitral regurgitation, mild aortic regurgitation, a thickening of the mitral and aortic valve leaflets, and a slight enlargement of the left ventricle and atrium were seen (Fig. 2ab). The functions of the left ventricle were measured normal. The patient was diagnosed with acute rheumatic fever with severe carditis. Also, in the 24-hours rhythm Holter recording atrioventricular dissociation was observed (Fig 3a). Prednisolone was started with anti-congestive therapy. At the 24th hour of treatment, the pain in the back and knees was completely resolved. A decrease in the PR interval was observed throughout the treatment (Fig. 3b). His complaints improved and the syncope did not occur again. In the second week of treatment, an electrocardiographic change was not observed other than mild PR prolongation (Fig. 3c). In the third month of follow up, it was seen that the PR interval was normal (Fig. 3d).

Written informed consent was obtained from the patient's parent.

\section{Discussion}

The delay of the impulse from the atrium to the ventricle leads to the prolongation of the PR interval. Aside from acute rheumatic fever, the PR prolongation can be detected in congenital heart diseases, ischemic heart diseases, connective tissue diseases, healthy people, and athletes. Moreover, it is usually asymptomatic. However, when the first-degree atrioventricular block becomes evident, it causes the atrial systole to become close to the preceding ventricular systole. Atrial contraction occurs against closed atrioventricular valves before complete atrial filling. Therefore, the ventricular filling is insufficient and cardiac output decreases. As a result of this, some symptoms like syncope and presyncope may emerge. ${ }^{2}$ In a study addressing the long-term outcome of the prolongation of the PR segment in adults, it was determined that there was a relationship between the first-degree atrioventricular block, risks of atrial fibrillation, the necessity for pacemaker implantation, and mortality. ${ }^{6}$

The occurrence of a loss of atrioventricular synchronization and hemodynamic impairment that formed due to VVI pacing with retrograde ventriculoatrial conduction is called Pacemaker syndrome. ${ }^{7}$ In those who do not have a pacemaker and have a marked First-degree atrioventricular block, when the $\mathrm{P}$ wave is very close to the previous QRS wave, hemodynamic alterations relative to a loss of atrioventricular synchronization occur. This situation is called pacemaker-like syndrome or pseudo-pacemaker syndrome in the literature. ${ }^{2,8}$ In patients with a marked first degree atrioventricular block, the symptoms related to our patient are connected to this atrioventricular dyssynchrony.

In acute rheumatic fever, some rhythm problems are seen more frequently other than PR prolongation. The relationship, especially between acute rheumatic fever and accelerated junctional rhythm, has been reported., ${ }^{3,9}$ In our patient's electrocardiography, the observation of the $\mathrm{P}$ wave immediately after the preceding QRS and especially the retrograde $\mathrm{P}$ wave led us to believe that accelerated junctional rhythm was seen. Although the shortening of the PR interval was observed with treatment, the morphology and axis of the $\mathrm{P}$ wave did not change.

In acute rheumatic fever, although PR prolongation is frequently seen, we have not come across PR prolongation in the literature as seen in our patient. Pacemaker-like syndrome is rarely seen, and it is important 


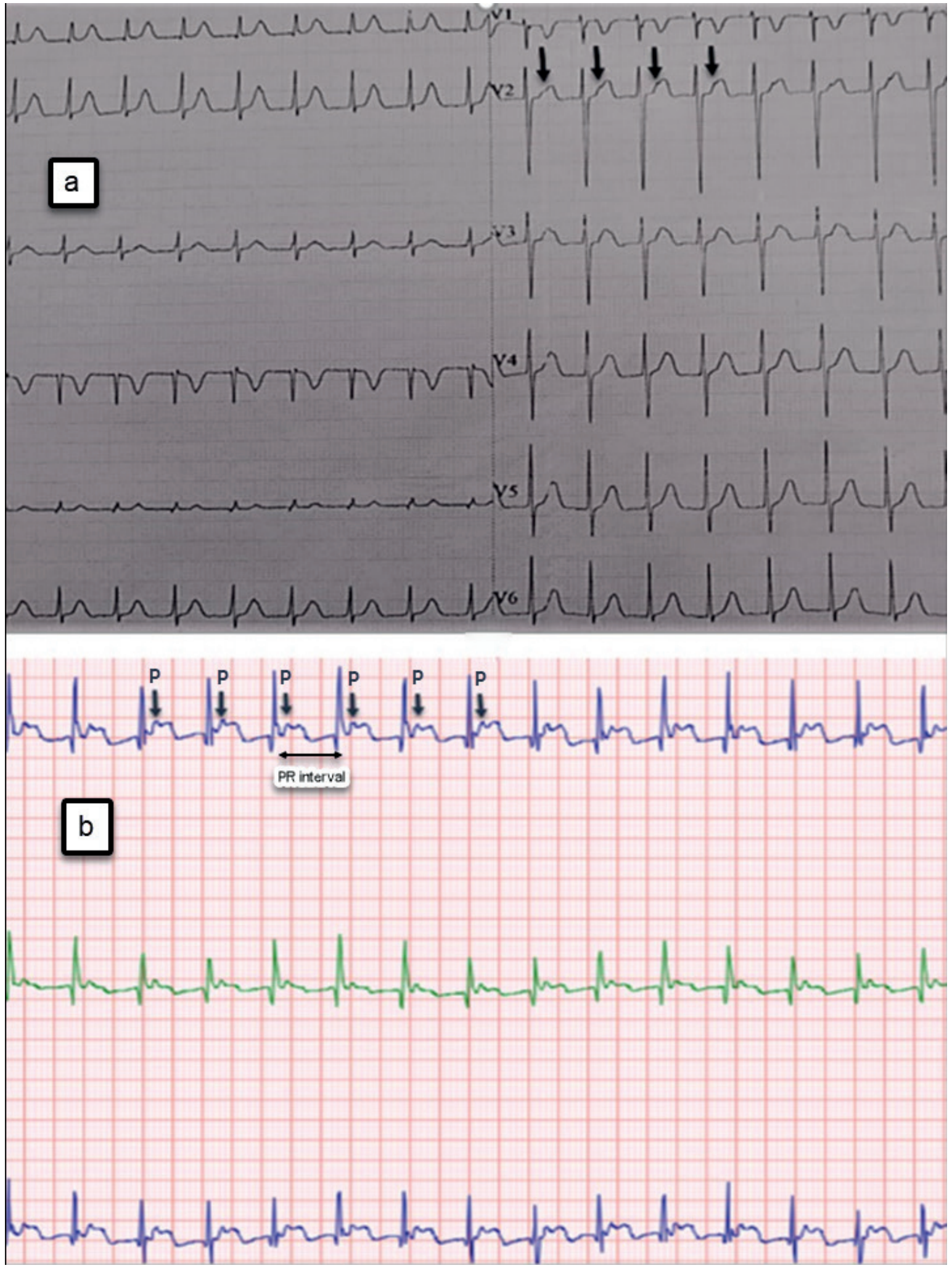

Fig. 1. The $\mathrm{P}$ wave was regularly seen at the onset of the $\mathrm{T}$ wave immediately after the QRS wave with extremely prolonged PR interval and mild tachycardia. 12-lead surface electrocardiography (a), a 24-hours rhythm Holter recording (b). 


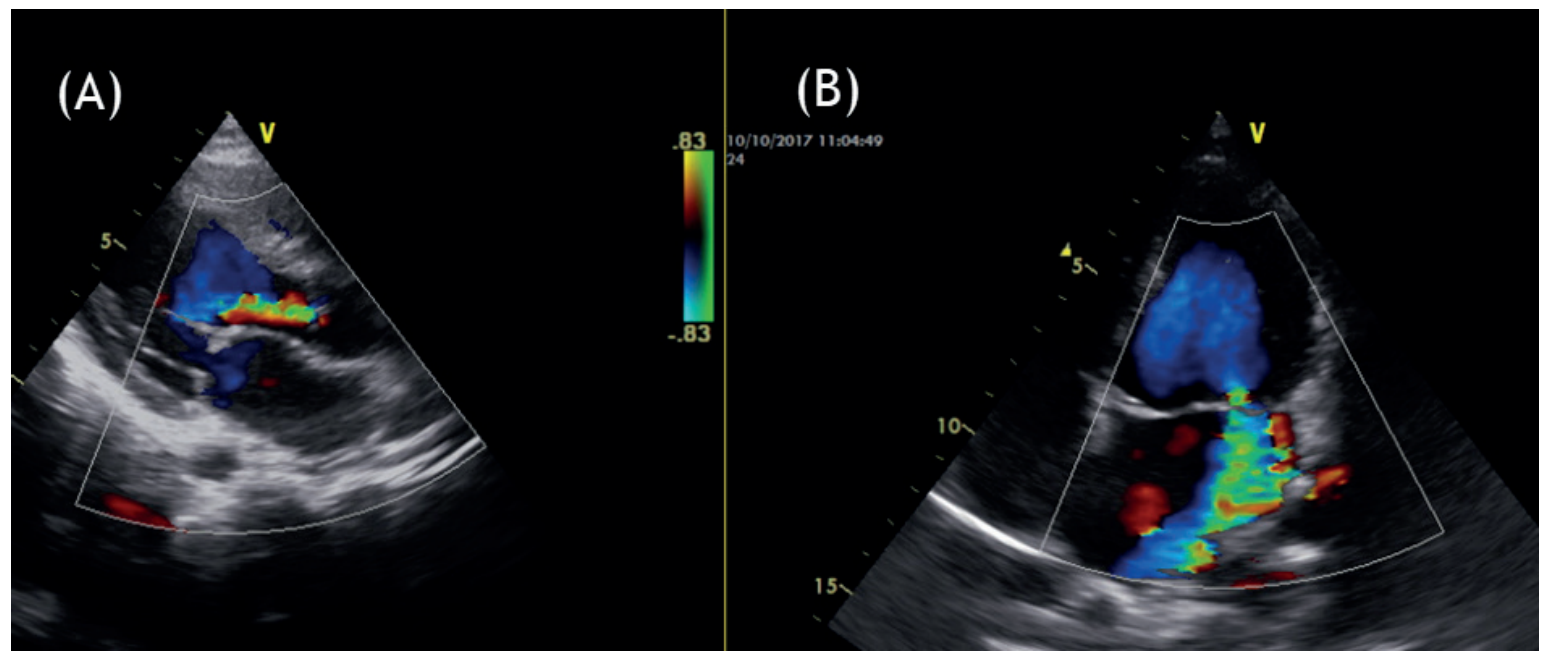

Fig. 2. 1st-degree aortic insufficiency (a) and 3rd-degree mitral insufficiency (b) with a mild enlargement were seen in the left chambers of the heart on the transthoracic echocardiography.
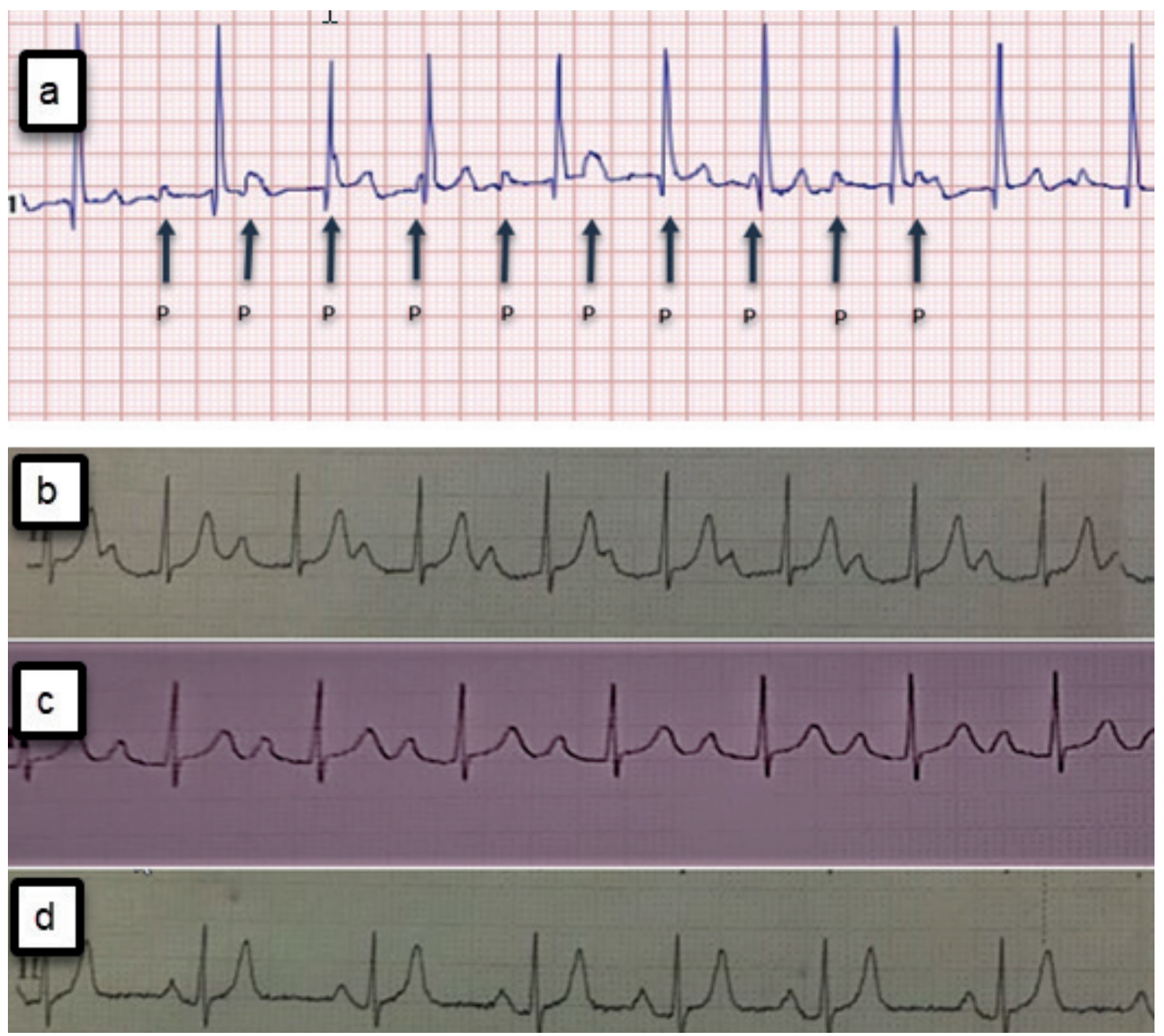

Fig. 3. Before the treatment; atrioventricular dissociation seen on a 24-hours rhythm Holter recording (a). In the 24th hour of treatment (b); it is seen that the PR interval shortened compared to before treatment, and the $\mathrm{P}$ wave is seen at the end of the $\mathrm{T}$ wave. The second week of treatment (c); the third month of treatment (d), the PR interval (0.18 seconds) was found to be normal for the age group. 
in terms of requiring pacemaker implantation (class IIa recommendation). ${ }^{10}$ In our patient, the inflammatory process was suppressed, bringing the PR prolongation back to normal, and the symptoms disappeared, and there was no need for a pacemaker.

In conclusion, clinicians may experience syncope or Adams-Stokes attacks in acute stages due to the rhythm problems that accompany acute rheumatic fever. Situations that cause atrioventricular dyssynchronization like in a complete atrioventricular block or as in our patient can cause decreases in cardiac output along with syncope or presyncope attacks. Pacemaker-like syndrome in a child is being reported for the first time with this article.

\section{REFERENCES}

1. Jones TD. The diagnosis of rheumatic fever. JAMA 1944; 126: 481-484.

2. Gewitz MH, Baltimore RS, Tani LY, et al; American Heart Association Committee on Rheumatic Fever, Endocarditis, and Kawasaki Disease of the Council on Cardiovascular Disease in the Young. Revision of the Jones criteria for the diagnosis of acute rheumatic fever in the era of Doppler echocardiography: a scientific statement from the American Heart Association. Circulation 2015; 131: 1806-1818.

3. Clarke M, Keith JD. Atrioventricular conduction in acute rheumatic fever. Br Heart J 1972; 34: 472-479.

4. Alimurung MM, Massell BF. The normal PR interval in infants and children. Circulation 1956; 13: 257 262.
5. Barold SS, Ilercil A, Leonelli F, Herweg B. First-degree atrioventricular block. J Interv Card Electrophysiol 2006; 17: 139-152.

6. Cheng S, Keyes, MJ, Larson MG et al. Long-term outcomes in individuals with a prolonged PR interval or first-degree atrioventricular block. JAMA 2009; 301: 2571-2577.

7. Ellenbogen KA, Gilligan DM, Wood MA, Morillo C, Barold SS. The pacemaker syndrome-a matter of definition. Am J Cardiol 1997; 79: 1226-1229.

8. Kim YH, O'Nunain S, Trouton $\mathrm{T}$, et al. Pseudopacemaker syndrome following inadvertent fast pathway ablation for atrioventricular nodal reentrant tachycardia. J Cardiovasc Electrophysiol 1993; 4: 178182.

9. Karacan M, Isikay S, Olgun H, Ceviz N. Asymptomatic rhythm and conduction abnormalities in children with acute rheumatic fever: 24-hour electrocardiography study. Cardiol Young 2010; 20: 620-630.

10. Epstein AE, DiMarco JP, Ellenbogen KA, et al; American College of Cardiology/American Heart Association Task Force on Practice Guidelines (Writing Committee to Revise the ACC/AHA/ NASPE 2002 Guideline Update for Implantation of Cardiac Pacemakers and Antiarrhythmia Devices); American Association for Thoracic Surgery; Society of Thoracic Surgeons. ACC/AHA/HRS 2008 Guidelines for Device-Based Therapy of Cardiac Rhythm Abnormalities: a report of the American College of Cardiology/American Heart Association Task Force on Practice Guidelines (Writing Committee to Revise the ACC/ AHA/NASPE 2002 Guideline Update for Implantation of Cardiac Pacemakers and Antiarrhythmia Devices): developed in collaboration with the American Association for Thoracic Surgery and Society of Thoracic Surgeons. Circulation 2008; 117: e350-e408. 